\title{
Nationwide descriptive study of COVID-19 in children below the age of 14 years in Sri Lanka
}

\author{
*M N S Cabraal ${ }^{1}$, R I U Samarawickrama ${ }^{1}$, K A R R Kodithuwakku ${ }^{1}$, S D Viswakula ${ }^{2}$, S R Lantra ${ }^{1}$
}

Sri Lanka Journal of Child Health, 2021; 50(1): 103-109

\begin{abstract}
Background: Corona virus disease 2019 (COVID19 ) is caused by a novel corona virus which originated in China and spread worldwide to become a global pandemic.
\end{abstract}

Objectives: To identify the demographic and clinical characteristics of children below the age of 14 years with COVID-19 in Sri Lanka.

Method: This was a retrospective, cross sectional descriptive study. Data of all COVID-19 positive patients below age of 14 years detected in Sri Lanka from $16 / 03 / 2020$ to $20 / 09 / 2020$ were analysed with $\mathrm{R}$ version 4.0.2, $\mathrm{R}$ Studio 1.3.959 and SPSS version 27. Descriptive plots and tables were obtained.

Results: During the study period, a total of 78 patients below the age of 14 years were detected in Sri Lanka. This constituted $2.4 \%$ of the total number of patients in the country. Children of all age groups were affected, $33.3 \%$ belonging to the $1-5$ year age group. Of the total, $55.1 \%$ were asymptomatic, $42.3 \%$ had mild disease and $2.6 \%$ had moderate disease. Common clinical manifestations were dry cough and fever. Median duration of hospital stay was 18 days. There were 53 local patients and 25 imported patients; $78.3 \%$ had a close family member diagnosed with COVID-19.

Conclusions: During the 6 month study period 78 COVID-19 positive patients below the age of 14 years were detected in Sri Lanka. Of them 55.1\% were asymptomatic, $42.3 \%$ had mild disease and $2.6 \%$ had moderate disease. Common clinical manifestations were dry cough and fever; $78.3 \%$ had a close family member diagnosed with COVID-19.

${ }^{1}$ National Institute of Infectious Diseases, Sri Lanka, ${ }^{2}$ Department of Statistics, University of Colombo, Sri Lanka

*Correspondence: cabraalsherica@gmail.com

https://orcid.org/0000-0003-3414-1533

(Keceived on 20 November 2020: Accepted after revision on 18 December 2020)

The authors declare that there are no conflicts of interest

Personal funding was used for the project.

Open Access Article published under the Creative

Commons Attribution CC-BY (c) (i) License
DOI: http://dx.doi.org/10.4038/sljch.v50i1.9410

(Key words: COVID-19, SARS CoV-2, paediatric age group, WHO, epidemiological)

\section{Introduction.}

Corona Virus disease 2019 (COVID-19) is caused by a novel corona virus named severe acute respiratory syndrome corona virus 2 (SARS CoV-2) which originated in Wuhan city in China in December 2019 ${ }^{1,2}$. The disease soon spread worldwide infecting several millions and killing more than a million people around the world ${ }^{3}$. It was declared a global pandemic by the World Health Organisation (WHO) on 11th March 20204. The disease is transmitted mainly by droplet infection ${ }^{5,6}$. At present there is no effective treatment and no vaccine available to prevent the disease $e^{7,8}$. The incidence and clinical manifestations of the disease may differ in children compared to adults ${ }^{9}$. Furthermore, the clinical course of the disease may vary in different countries. Only a few studies have been conducted in the paediatric age group ${ }^{10,11,12}$. To the best of our knowledge this is the only study which analysed paediatric COVID-19 patients in Sri Lanka. In Sri Lanka, only patients under the age of 14 years are admitted to paediatric wards. Hence it was decided to study only children below the age of 14 years.

\section{Objectives}

- To identify the demographic and clinical characteristics of children below the age of 14 years with COVID-19 and the transmission pattern of the disease in Sri Lanka.

- To identify the source of infection, to define the epidemiological stage of the disease in the country and to identify the pattern of the disease by drawing the epidemiological curve.

\section{Method}

This was a retrospective cross-sectional study of a descriptive nature. All COVID-19 positive paediatric patients below the age of 14 years detected in Sri Lanka from $16^{\text {th }}$ March 2020 to $20^{\text {th }}$ September 2020 were included in this study. A positive patient was defined as a child with a positive polymerase chain reaction (PCR) test for COVID-19 from a nasopharyngeal swab. The participants were from the paediatric units of the National Institute of 
Infectious Diseases (NIID), Angoda, Colombo East Base Hospital (CEBH) Mulleriyawa and Welikanda Base Hospital (BH) which were the designated COVID treatment centres in the country.

Ethical issues: Ethical clearance for the study was obtained from the Ethical Review Committee of the Faculty of Medicine, University of Colombo (No. EC-20-051) on 17/09/2020. Administrative approval to collect data was obtained from the Heads of NIID Angoda, CEBH Mulleriyawa and $\mathrm{BH}$ Welikanda through the Director General of Health Services. Being a retrospective study, no informed consent was possible. Confidentiality is assured.

The data was collected perusing patients' records. Data of all paediatric patients below the age of 14 years recorded in the National Statistics were included in this study. Few missing data were obtained by contacting the parent or the guardian via phone. The data were accessed only by the Investigators of the study. Data were entered first on a data collection sheet and then transferred to the $\mathrm{R}$ version 4.0.2 and R Studio 1.3.959 AND SPSS (version 27) for analysis.

\section{Results}

As of 20/09/2020, a total of 3272 COVID-19 positive patients were detected in Sri Lanka, of which 78 were children below the age of 14 years. This constituted $2.4 \%$ of the total number of patients. The breakdown of patients according to the hospital they were admitted to, is shown in Table 1.

Table 1: Breakdown of patients according to hospital

\begin{tabular}{|l|c|}
\hline \multicolumn{1}{|c|}{ Hospital } & Number \\
\hline National Institute of Infectious Diseases & 56 \\
\hline Colombo East Base Hospital & 14 \\
\hline Welikanda Base Hospital & 08 \\
\hline Total & $\mathbf{7 8}$ \\
\hline
\end{tabular}

The age distribution of the children is shown in Figure 1. There were $8(10.3 \%)$ infants, $26(33.3 \%)$ in the $1-5$ year age group, $19(24.4 \%)$ in the $5-10$ year age group and $25(32.1 \%)$ in the 10-14 year age group. The mean age of the participants was 6.51 years.

Figure 2 shows the gender distribution of the patients. The female: male ratio was 0.86:1.0.

Figure 3 shows the distribution of patients. Imported cases were patients who directly arrived from abroad and were detected at the airport or while being quarantined.

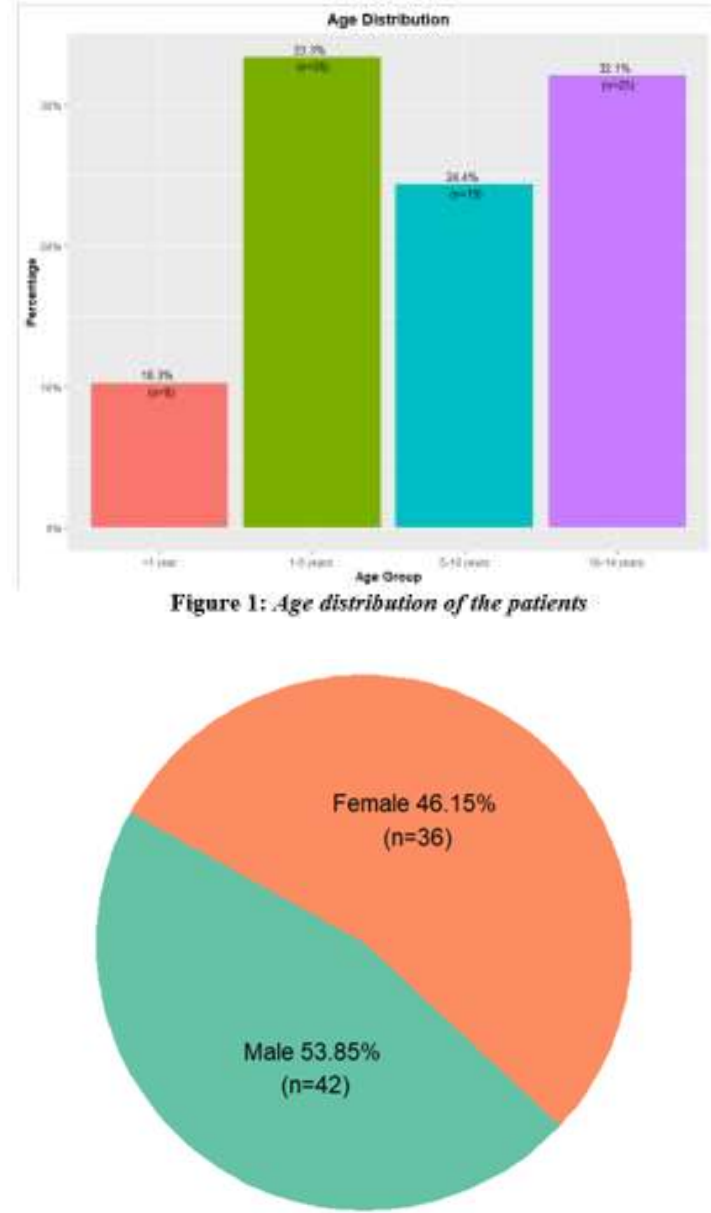

Figure 2: Gender distribution of the patients

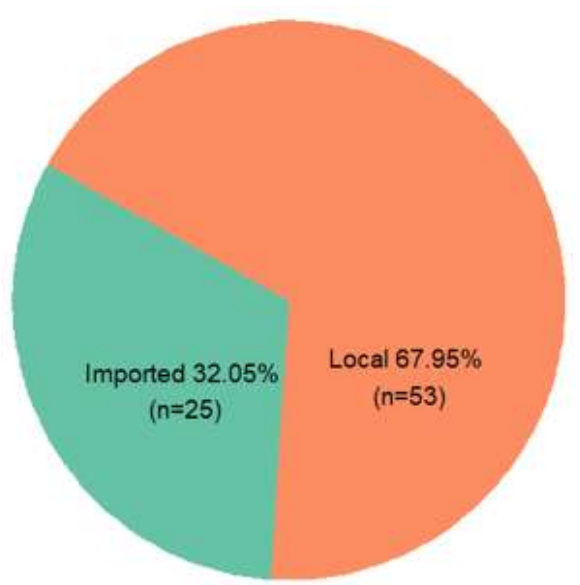

Figure 3: Distribution of patients

Figure 4 shows the distribution of imported patients according to country. 


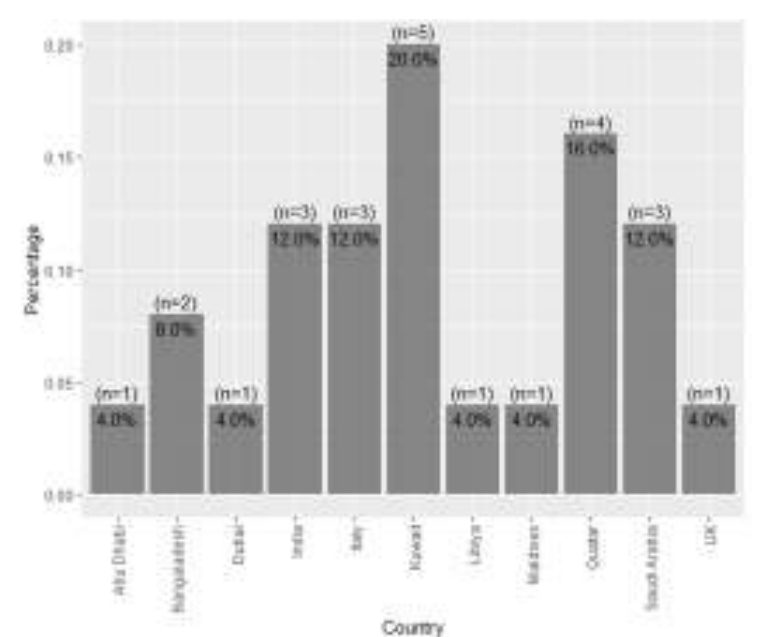

Fipure 4: Distribution of imported parients acconding so country

Figure 5 shows the distribution of local patients according to Administrative District.

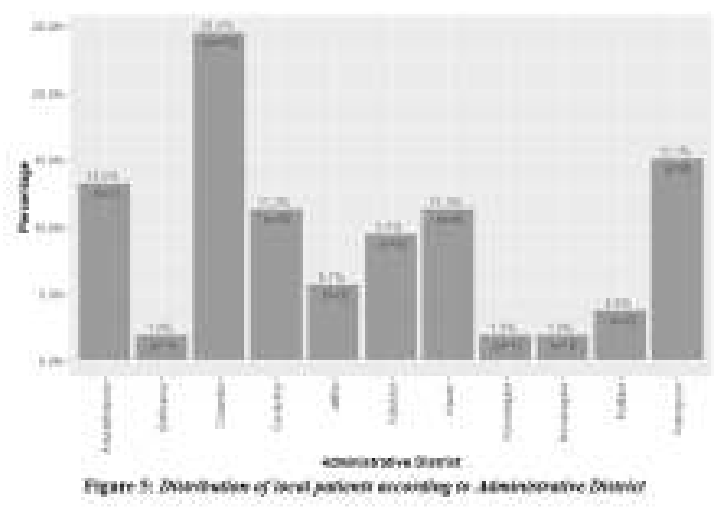

Figure 6 shows the symptom distribution of the patients. Thirty five $(45 \%)$ patients were symptomatic and $43(55 \%)$ were asymptomatic.

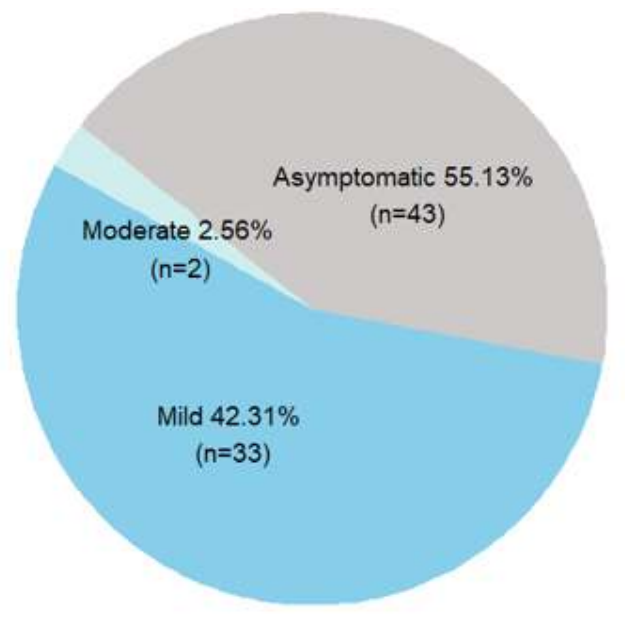

Figure 6: Symptom distribution of the patients

Figure 7 shows the distribution of the clinical features.

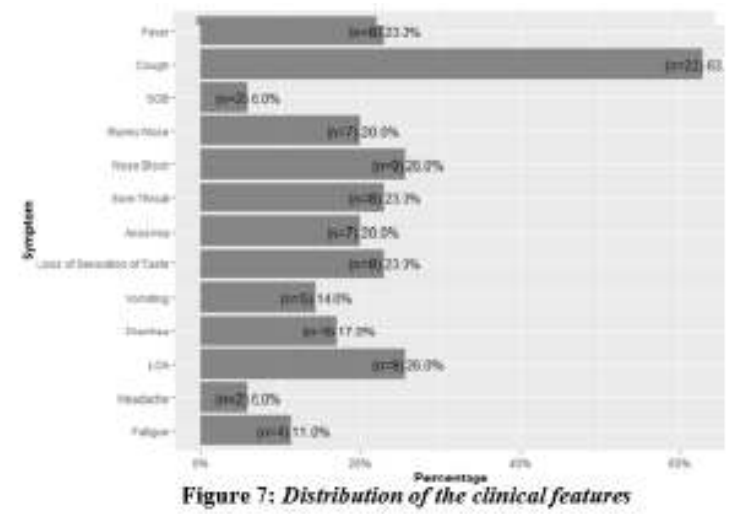

Figure 8 shows the source of contact.

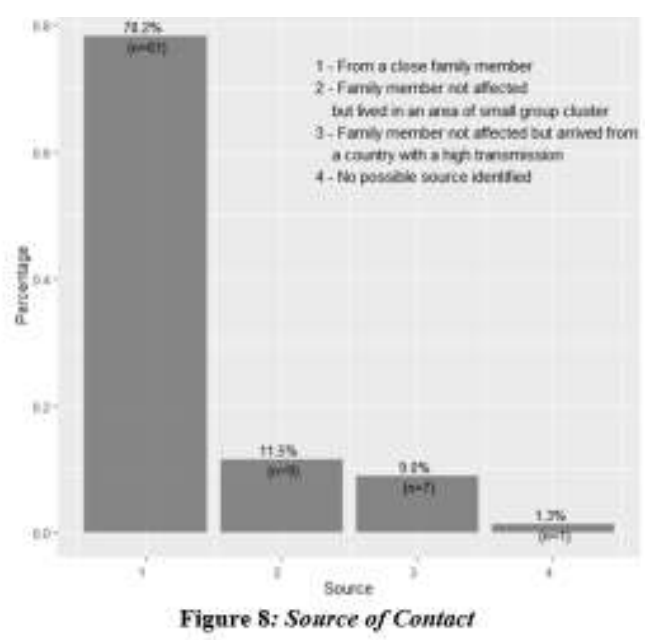

Figure 9 shows the distribution according to epidemiologic stage. Of the local cases, 4 (5.13\%) belonged to family clusters (epidemiological stage $3 a), 48(61.54 \%)$ were from small group clusters (stage $3 \mathrm{~b}$ ) and $1(1.28 \%)$ child was identified as a sporadic case (stage 2).

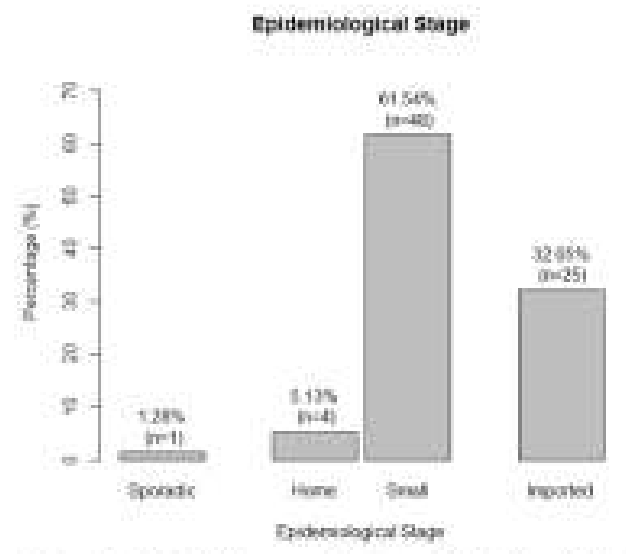

Figure 9; Distribunion according ro epidemiological srage

Figure 10 shows the composition of the small group clusters. Seventeen $(35.4 \%)$ children were from the Navy cluster, 8 (16.7\%) from the Kandakadu cluster, 6 (12.5\%) from Bandaranayakepura Mawatha 
cluster, 7 (14.6\%) from Puttalam and 3 (6.2\%) each from Jaffna and Negombo clusters.

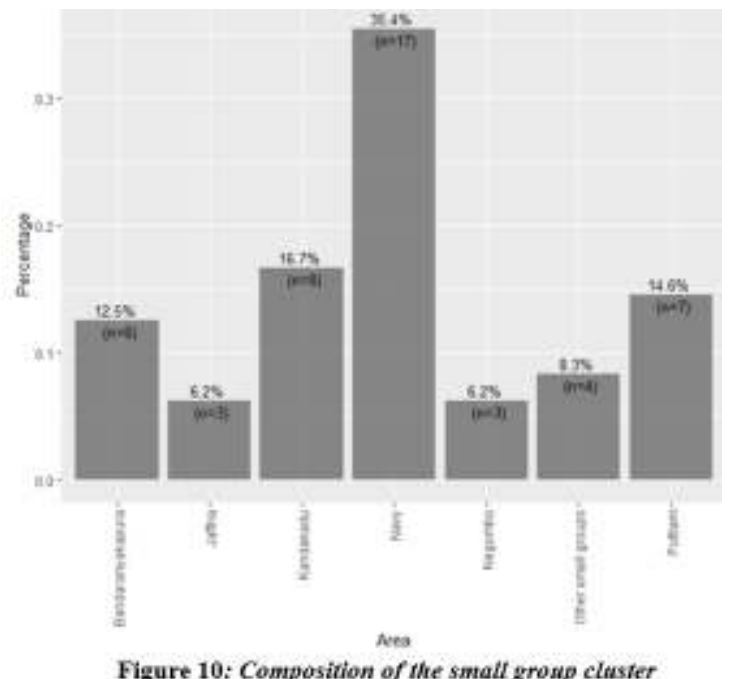

Figure 11 shows the epidemiological curve of paediatric patients and Figure 12 shows the epidemiological curve of all patients. The epidemiological curve of paediatric patients rises intermittently and has multiple peaks and follows the curve of the total patients.

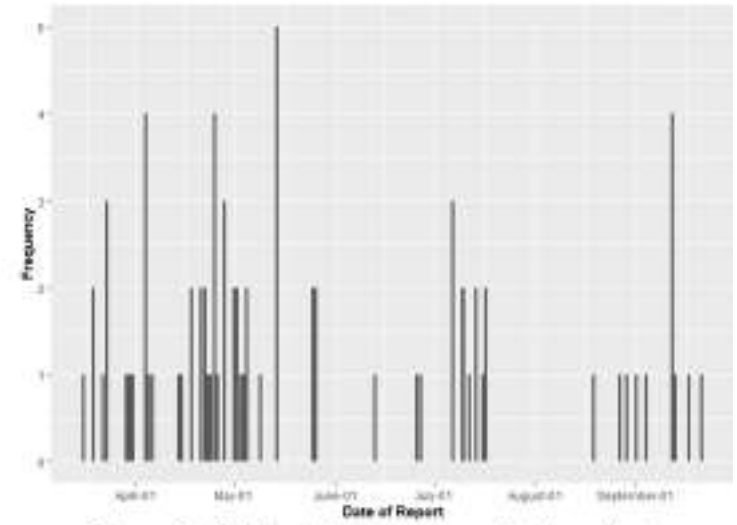

Figure 11: Epidemiology curve - paediatric patients

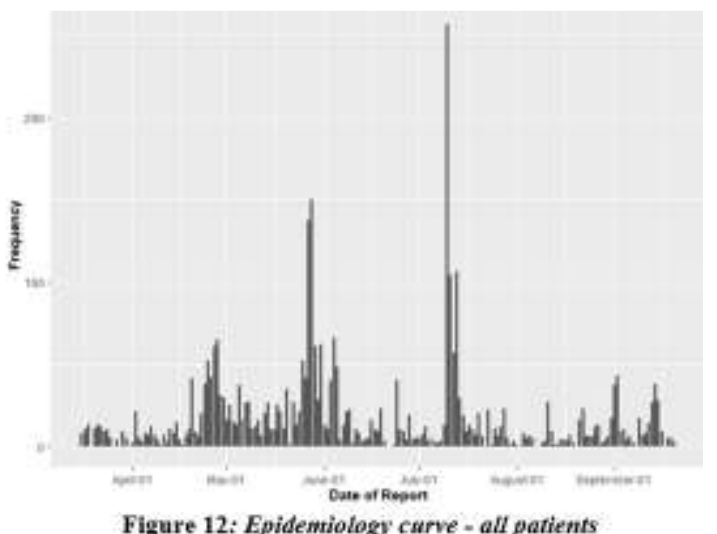

Table 2 shows the patient management summary. As per our national guidelines, although all the COVID19 positive children were admitted to a COVID treatment centre, $44(56.4 \%)$ did not require any treatment. The antibacterial agent used for treatment was azithromycin. Two were treated with bronchodilators and one required artificial ventilation.

Table 2: Patient management summary

\begin{tabular}{|l|c|}
\hline Method of management & Number (\%) \\
\hline No treatment needed & $44(56.4)$ \\
\hline Symptomatic treatment & $24(30.8)$ \\
\hline Treated with antibiotics & $10(12.8)$ \\
\hline
\end{tabular}

Figure 13 shows the time taken for the patient to be non-infectious. Initially, the patients were considered non-infectious when two consecutive PCR tests were negative. Ten $(12.8 \%)$ patients became non-infectious in less than a week, 17 $(21.8 \%)$ patients each in 1-2weeks and 2-3weeks respectively, $12(15.4 \%)$ patients in $3-4$ weeks and $10(12.8 \%)$ patients after 4 weeks. Later, when serology and cycle threshold (CT) value were both considered, 4 (5.1\%) patients took $1-2$ weeks, 3 $(3.9 \%)$ patients each took $<1$ week and $2-3$ weeks.

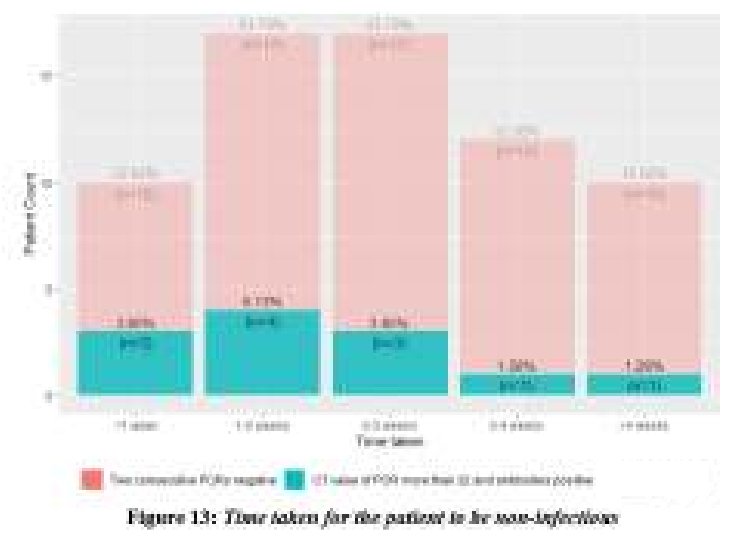

Figure 14 shows the length of hospital stay. The length of the hospital stay has a slight positively skewed pattern. The median length of stay was 18 days and inter-quartile range was 11-26 days.

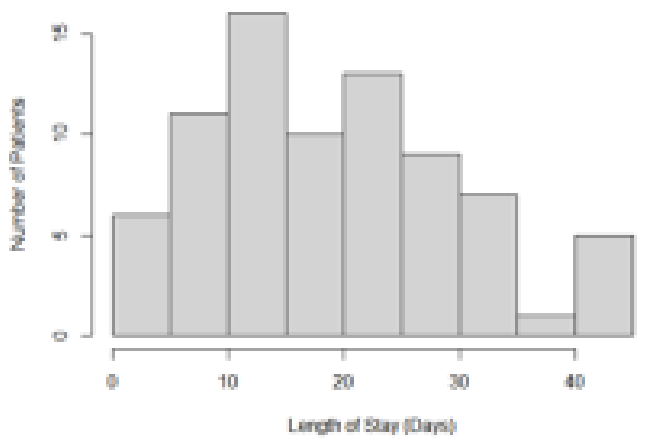

Figure 14: Length of hospital stay

\section{Discussion}

In this study, we analysed the data of all 78 children below the age of 14 years diagnosed with COVID19 in Sri Lanka from 16/03/2020 to $20 / 09 / 2020$. 
Incidentally, our study period coincided with the first wave of the disease in the country. The principal investigator and three co-investigators were responsible for managing the patients admitted to NIID. All these children, including those with comorbid conditions, recovered and have been discharged home. Contrary to what we expected at the beginning of the pandemic, based on the experience we had about other viruses which affect more children, less children were affected with COVID-19. This may be due to the restricted movements of children due to the lock down of the country and closure of schools resulting in less chances of getting exposed to the virus. The heterologous protective effect of BCG vaccine ${ }^{13}$ and the lower expression of ACE 2 receptor in children which the SARS-CoV-2 use to enter the host cells ${ }^{14}$ may also explain the lesser incidence.

Children of all age groups were affected. The maximum number of patients belonged to the 1-5 year age group. Although males were affected more than females, there was no significant statistical difference in gender distribution. In our study, slightly more than half of the patients were asymptomatic. While a study in India showed 58\% of patients were asymptomatic ${ }^{10}$, in China $94.1 \%$ and in Italy $97.5 \%$ were symptomatic ${ }^{11,12}$. Even the symptomatic children had mild disease, the commonest clinical feature being a dry cough. Other clinical features were fever, sore throat, dyspnoea, nasal congestion, vomiting, diarrhoea, anosmia and loss of sensation of taste, loss of appetite, headache and malaise. None of the children developed severe disease. In Italy, $19.6 \%$ children developed complications like interstitial pneumonia and severe acute respiratory illness ${ }^{12}$. Children with symptoms like malaise, fever and dry cough were considered to be suffering from mild disease. Those with moderate disease had pulmonary involvement. Three patients had comorbid conditions. A two and a half month old baby who developed respiratory distress required artificial ventilation. The 2D echocardiogram of the baby revealed a cortriatriatum and surgery was performed. Following a complicated post-operative period, the baby recovered. The other two were known wheezers who developed acute exacerbations. Although some children with hyper-inflammatory shock showing features of atypical Kawasaki disease were identified in the United Kingdom ${ }^{15}$ and other European countries, we did not come across a single child presenting with a similar picture.

Our first COVID-19 patient, a child of a COVID-19 positive father, was reported on $16^{\text {th }}$ March 2020. Since then, the number of patients detected were low, mostly being either returnees from abroad or their contacts. These patients formed either family or small group clusters. From the last week of April to mid-May, a cluster of patients was reported from the Sri Lanka Navy. During this period, the number of paediatric patients also increased. They were either children or close contacts of Navy officers. During the next one and a half months, the positive patients were confined mostly to children of repatriates from Middle Eastern and other countries. Then again in July, there was another cluster of patients originating from the Kandakadu Rehabilitation Centre and the number of paediatric patients increased. There were $53(68 \%)$ local cases and $25(32 \%)$ imported cases. The local cases reached the level of small group clusters passing beyond sporadic and family clusters. Therefore, at the end of the first wave, the epidemiological stage for paediatric patients was stage $3 \mathrm{~b}$ and there was no evidence to suggest community spread (stage 4) of the disease in Sri Lanka. The epidemiological curve of paediatric patients shows an intermittent increase in the number of patients, with multiple peaks indicating exposure from different sources and clustering of patients. Furthermore, it follows the pattern of the curve of the total patients closely. The epidemiological curve in China showed that there was a rapid increase of patients in the early stage of the epidemic and then a gradual decrease which indicates community spread of the disease ${ }^{16}$.

Our study shows that the majority of paediatric patients $(78.2 \%)$ acquired the disease by close contact with family members with COVID-19. In Italy $^{12} 67.3 \%$ and in China ${ }^{11} 66 \%$ of children had at least one parent tested positive for SARS CoV-2 infection. Furthermore, another $11.5 \%$, although they did not have an infected family member, belonged to a small group cluster indicating close contact with adults in the neighbourhood. Another $9 \%$ arrived from countries with high transmission of the disease possibly getting exposed to adults during travelling. We could not identify a possible source of contact only in one patient $(1.3 \%)$.

Our practice was to admit all the patients with a positive PCR test to a COVID treatment centre. Initially, serial PCR tests were performed and when two consecutive PCR tests done at least 24 hours apart were negative, the patient was considered noninfectious and was discharged from the hospital. Later, with the availability of serology testing, the discharge criteria were changed. Then, the patient was considered to be non-infectious when CT value of the PCR test was more than 32 with a positive serology. In our study the median duration of hospital stay was 18 days. In China the median time from onset to cure was 16 days (6 to 39 days) ${ }^{11}$ and in Turkey the median length of hospital stay was 5 days (4 to 10 days) ${ }^{17}$. Several studies have shown that the PCR tests can be positive to a variable length of time ${ }^{10,18}$. However, the test does not differentiate 
viable from non-viable viral particles ${ }^{19}$ and the degree of infectivity after 14 days is not clear.

Most of our patients did not require any treatment. Some required only symptomatic treatment like nasal decongestants, antihistamines or probiotics. Ten (12.8\%) patients with cough were given azithromycin mainly because a French study which combined hydroxychloroquine with azithromycin resulted in better viral clearance ${ }^{20}$. The baby with congenital heart disease required admission to the intensive care unit and specific management for her condition. The 2 children with wheezing required inhaled bronchodilator therapy. At the time of preparing this report, unfortunately our country was experiencing a second wave of COVID-19. We intend to analyse the data of the paediatric patients affected to assess whether our experience with the first wave helped in managing the second wave.

This study has several limitations. By the time the serology testing was made available in the country in the latter part of the first wave, some patients had a hospital stay of more than 10 days as their serial PCR tests were positive. The delayed testing of serology of these patients interfered with our results and even though we experienced the shortening of duration of the hospital stay we were unable to prove it statistically. Since younger children were unable to express symptoms such as anosmia and loss of sensation of taste, the actual percentages of these symptoms may be higher than the shown figures. However, our study has a strong case as it provides valuable information about the demographic and clinical characteristics and transmission patterns in paediatric COVID-19. This would help in managing a possible increase in patients in the future. Since children acquire the disease from close contact with either family members or other adults, the importance of adhering to preventive measures among family members should be emphasized. In our study all the children, except two, were either asymptomatic or had mild disease. Whether admitting asymptomatic patients to treatment centres is necessary should be addressed. Therefore, we recommend reviewing the admission criteria for the effective management of the resources of the hospitals in case of an exponential rise in number of patients. Since almost one third of our patients were imported cases, screening and quarantining of people arriving from abroad should be continued at all possible ports of entry.

\section{Conclusions}

During the 6 month study period 78 COVID-19 positive patients below the age of 14 years were detected in Sri Lanka. Of them 55.1\% were asymptomatic, $42.3 \%$ had mild disease and $2.6 \%$ had moderate disease. Common clinical manifestations were dry cough and fever; $78.3 \%$ had a close family member diagnosed with COVID-19.

Acknowledgements.

We thank all the patients included in this study and the Heads of Institutions of the three hospitals for allowing us to retrieve data from patient records.

\section{References}

1. Wei-jie Guan, Zheng-yi Ni, Yu Hu, Wenhua Liang, Chun-quan Ou, Jan-xing He, et al. Clinical characteristics of coronavirus disease 2019 in China. New England Journal of Medicine 2020; 382:1708-20. https://doi.org/10.1056/NEJMoa2002032 PMid: 32109013 PMCid: PMC7092819

2. Liu YC, Kuo RL, Shih SR. COVID-19: The first documented coronavirus pandemic in history. Biomedical Journal 2020; 43(4): 328-33.

https://doi.org/10.1016/j.bj.2020.04.007

PMid: 32387617 PMCid: PMC7199674

3. WHO weekly operational update, 2nd October 2020

4. Cucinotta D, Vanelli M. WHO Declares COVID-19 a Pandemic. Acta Bio-medica 2020; 91: 157-60.

5. CDC. How COVID-19 Spreads. Centers for Disease Control and Prevention; (2019). Available from: https://www.cdc.gov/coronavirus/2019ncov/prepare/transmission.html (accessed March 20, 2020).

6. Parasher A. COVID-19: Current understanding of its pathophysiology, clinical presentation and treatment. Postgraduate Medical Journal Published Online First: 25 September 2020. https://doi.org/10.1136/postgradmedj2020-138577

PMid: 32978337

7. Beigel JH, Tomashek KM, Dodd LE, Mehta AK. Remdesivir for the treatment of Covid-19 - Final Report. New England Journal of Medicine 2020; 383:1813-1826

https://doi.org/10.1056/NEJMoa2007764

PMid: 32445440 PMCid: PMC7262788

8. Paltiel AD, Schwartz JI, Zheng A, Walensky RP. COVID-19 vaccine: 
Implementation over efficacy. November 19,2020

https://doi.org/10.1377/hlthaff.2020.02054

PMid: 33211536

9. Yuki K, Fujiogi M, Koutsogiannaki S. COVID-19 pathophysiology: A review. Clinical Immunology 2020; 215: 108427.

https://doi.org/10.1016/j.clim.2020.10842 7

PMid: 32325252 PMCid: PMC7169933

10. Sarangi B, Reddy VS, Oswal JS, Malshe N, Patil A, Lalwani CS. Epidemiological and clinical characteristics of COVID-19 in Indian children in the initial phase of the pandemic; A cross sectional study. Available

from:https://www.researchgate.net/publica tion $/ 342321773$

11. Guo C-X, He L, Yin J-Y, Meng X-G, Tan $\mathrm{W}$, Yang G-P, et al. Epidemiological and clinical features of paediatric COVID19. BMC Medicine 2020; 18: Article No.250.

https://doi.org/10.1186/s12916-02001719-2

PMid: 32762696 PMCid: PMC7408975

12. Garazzino S, Montagnani C, Dona D, Meini A, Felici E, Vergine G. et al. Multicentre Italian study of ARS-CoV-2 infection in children and adolescents, preliminary data as at 10 April 2020. Eurosurveillance 2020; 25(18): 2000600. doi:10.2807/15607917.ES.2020.25.18.200 0600 .

https://doi.org/10.2807/15607917.ES.2020 .25.18.2000600

PMid: 32400362 PMCid: PMC7219028

13. Gupta PK. New disease old vaccine: Is recombinant $\mathrm{BCG}$ vaccine an answer for COVID-19? Cellular Immunology 2020; 356: 104187.

https://doi.org/10.1016/j.cellimm.2020.10 4187

PMid: 32745670 PMCid: PMC7386780

14. Ni W, Yang X., Yang D, Bao J, Li R, Xiao $\mathrm{Y}$, et al. Role of angiotensin-converting enzyme 2 (ACE2) in COVID-19. Critical Care 2020; 24(1): 422. https://doi.org/10.1186/s13054-02003120-

0 .

https://doi.org/10.1186/s13054-020-

03120-0

PMid: 32660650 PMCid: PMC7356137

15. Riphagen S, Martinez CG, Wilkinson N, Theocharis P. Hyperinflammatory shock in children during COVID-19 pandemic. Lancet 2020; 395(10237): 1607-8. https://doi.org/10.1016/S01406736(20)310 94-1

16. Dong Y, Mo X, Hu Y, Qi X, Jiang F, Jiang $\mathrm{Z}$, et al. Epidemiology of COVID-19 among children in China. Pediatrics 2020; 145(6): e20200702;

https://doi.org/10.1542/peds.2020-0702

PMid: 32179660

17. Korkmaz MF, Türe E, Dorum BA, Kılıç ZB. The epidemiological and clinical characteristics of 81 children with COVID19 in a pandemic hospital in Turkey: An observational cohort study. Journal of Korean Medical Science 2020; 35(25): e236.

https://doi.org/10.3346/jkms.2020.35.e236 PMid: 32597047 PMCid: PMC7324269

18. Lan L, Xu D, Ye G, Xia C, Wang S, Li Y, $\mathrm{Xu} \mathrm{He}$, et al. Positive RT-PCR test results in patients recovered from COVID-19. JAMA 2020: 323(15); 1502-3.

https://doi.org/10.1001/jama.2020.2783

PMid: 32105304 PMCid: PMC7047852

19. Lauri A, Marisni PO. Potential limitations of molecular diagnostic methods in food safety. Genes and Nutrition 2009; 4(1):1 2. https://doi.org/10.1007/s12263-008-01061

PMid: 19067016 PMCid: PMC2654054

20. Gautret P, Lagier JC, Parola $P$, et al. Hydroxychloroquine and azithromycin as a treatment of COVID-19: results of an open-label non-randomized clinical trial. International Journal of Antimicrobial Agents 2020; 56(1): 105949.

https://doi.org/10.1016/j.ijantimicag.2020. 105949

PMid: 32205204 PMCid: PMC7102549 